\title{
Joint Effect of Alcohol use and Tobacco Smoke on All-Cause Mortality and Premature Death in China: A Cohort Study
}

Hongli Zhang

Xi'an Central Hospital

Bi Xueyuan

Xi'an Honghui Hospital

Zheng Nanbo

Xi'an Central Hospital

Chao Li

Xi'an Jiaotong University Health Science Center

Yan Kangkang ( $\nabla$ kky_hospital@163.com )

Research article

Keywords: Tobacco smoke, Alcohol use, Joint effect, Mortality, Cohort study

Posted Date: May 22nd, 2020

DOI: https://doi.org/10.21203/rs.3.rs-30164/v1

License: (c) (1) This work is licensed under a Creative Commons Attribution 4.0 International License.

Read Full License 


\section{Abstract}

Background Tobacco smoke and alcohol use were associated with several diseases, study on joint effect of smoke and drink was rare.

Objective This study aims to investigate the joint effect of tobacco smoke and alcohol use on all-cause mortality and premature death in a contemporary cohort.

Methods China Health and Retirement Longitudinal Study (CHARLS) was an ongoing nationally representative survey for subjects aged over 45 years in China, which performed every 2 years for total of 3 waves from 2011 to 2015 in China. We used weighted logistic regression model to estimate the joint effect of tobacco smoke and alcohol use on total mortality and premature death.

Results After adjusting for the confounders, the odd ratios (ORs) value of all-cause mortality were 1.47 (95\% Cl: 1.03-2.08) and 1.51 (95\% Cl: 1.09-2.10) in smoker and non-drinker and smoker and drinker separately. Compared with non-smoker and non-drinker, smoker and drinker increased the odds of premature death by 3.14 ( $95 \% \mathrm{Cl}: 1.56-6.34)$. In the subgroup analysis, there was a 5 -fold $(\mathrm{OR}=4.95$; $95 \% \mathrm{Cl}: 2.00-12.27)$ increase in the odds of premature death for female smoker and drinker.

Conclusion This study found a joint effect of tobacco smoke and alcohol use on all-cause mortality and premature death among a contemporary and nationally representative data in China. Our results suggested the joint effect was more pronounced in women, but further research was needed.

\section{Introduction}

Tobacco smoke is a well-established risk factors for many diseases including stroke, coronary heart disease (1). Additionally, several studies including the British Doctors Study (2), the American Cancer Society Cancer Prevention Study (3) and pooled analysis of Asia cohorts(4) have shown the increased risk of mortality from tobacco smoke. It has been reported that tobacco smoke is the second leading risk factor for death from any cause worldwide $(5,6)$ and was the leading cause of death among Chinese $\operatorname{men}(7)$.

Alcohol use is another leading risk factor for death and disability (8). Although some studies reported Jshaped association between alcohol use and all-cause mortality, which suggested that low alcohol use may confer some degree of protection $(9,10)$, this view was challenged by recent studies which use of mendelian randomization and meta-analyses $(8,11,12)$. These protective associations between moderate alcohol and health may, however, be explained by the effect of biases (e.g., study design, confounders, selection of participants) $(12,13)$.

Although the effect of tobacco smoke and alcohol use on death has been well documented separately, studies on the joint effect of these two leading risk factors on deaths or early death were still rare. 
Therefore, the aim of this study was to estimate the joint effect of tobacco smoke and alcohol use on allcause mortality and premature death using a Chinese nationally representative cohort data.

\section{Methods}

\section{Study population}

Data for this study was drawn from the national baseline and follow up database of the China Health and Retirement Longitudinal Study (CHARLS). The first baseline survey of this study was conducted in 2011-2012, which involved 17708 subjects. The details of study design for CHARLS has been reported previously $(14,15)$. In general, it is an ongoing nationally representative survey, which performed every 2 years for total of 3 waves from 2011 to 2015 in China. Adults aged 45 years or older living in China were enrolled in baseline survey, and been followed up in waves 2, 3 and 4. Subjects were chosen with a multi-stage stratified sampling design in 450 villages, 150 counties and 28 provinces to ensure the representativeness of the sample and can be weighted to obtain national estimates.

\section{Data Collection And Variable Definition}

Each subject was administered a survey interview which include the information on date of birth, gender, educational level (illiterate, Primary, Secondary/High School, College/University or above), marital status (Married/ Divorced/ Widowed, Unmarried), residence status (Rural, Urban)., tobacco smoking habits, alcohol consumption, height and weight, medicine usage and medical history. Blood was also taken for laboratory testing. We defined the history of cardiovascular (CVD) if subjects reported having history of stroke, heart failure or CHD. Overweight was defined as $24 \mathrm{~kg} / \mathrm{m}^{2} \leq \mathrm{BMl}<28 \mathrm{~kg} / \mathrm{m}^{2}$ and Obesity were defined as $B M I \geq 28 \mathrm{~kg} / \mathrm{m}^{2}$. Blood pressure was measured by Omron model HEM-7200. The SBP and DBP were calculated by averaging available 3 blood pressure measurements (approximately $45 \mathrm{~s}$ apart) for each subject. We defined hypertension as a SBP of $140 \mathrm{~mm} \mathrm{Hg}$ or more, or a DBP of $90 \mathrm{~mm} \mathrm{Hg}$ or more, or self-reported use of antihypertensive treatment. Diabetes was defined as hemoglobin $A_{1 C} \geq 6.5 \%$, use of anti- diabetic medication, or self-reported history of diabetes. Dyslipidemia was defined as use of dyslipidemia medication or having one of the following conditions: total cholesterol $\geq 6.19 \mathrm{mmol} / \mathrm{L}$, low density lipoprotein cholesterol $\geq 4.14 \mathrm{mmol} / \mathrm{L}$, or triglyceride $\geq 2.27 \mathrm{mmol} / \mathrm{L}$. Subjects are classified as tobacco smoker if he/she had ever smoker more 100 cigarettes in their life. An alcohol drinker was defined as a participant drinking alcoholic beverages at least once a month. participants were further divided into four groups: non-smoker/non-drinker, non-smoker/drinker, smoker/non-drinker, smoker/drinker.

linterviewees' status (dead or alive) were recorded in each wave however, death date were only recorded in wave 2 (2013 follow-up). We calculated the age of death from the interval between the date of birth iand the death date. In our current analysis, we defined premature death according to the average life 
expectancies in China in 2011, which was before age 72.7 years in men and 76.9 years in women (16). Detailed information about the data quality management has been estimated previously (17).

\section{Statistical analysis}

Summary statistics for the baseline characteristics and risk factors by gender were computed as the proportions or means, and compared across different smoke and drink status groups by using ANOVA or chi-square test. The joint effect of tobacco smoke and alcohol use on total mortality and premature death were estimated using weighted logistic regression model. Unadjusted and adjusted odds ratios (ORs) and their $95 \% \mathrm{Cls}$ were obtained. The multivariable model was adjusted for gender, age, educational level, current residence status, marital status, hypertension, dyslipidemia, diabetes, history of CVD, overweight or obesity. All reported $P$ values were 2-tailed, and values of $a<0.05$ were considered statistically significant. Analysis was performed with the Stata software version 15.0 (Stata Corporation).

\section{Results}

In this present study, we excluded 3.5\% (628/17708) participants, because of the missing values in age/gender $(n=495)$, tobacco smoke $(n=126)$, alcohol use $(n=7)$. Therefore, the remaining 17080 participants are eligible for inclusion in the present analysis. We found that $26.8 \%(4583 / 17080)$ of participants were both cigarette smokers and alcohol drinkers with a substantially higher prevalence in male subjects (52.7\% [4391/8332] in men and 2.19\% [192/8748] in women). The mean age of participants among different smoke and drink groups were range from 50.3 to 60.9 years, most participants were from rural area and married. The prevalence of overweight or obesity was higher in nonsmoker/non-drinker group. The prevalence of other cardiovascular related risk factors (hypertension, dyslipidemia, diabetes, history of CVD) was similar among four different smoke and drink groups (Table 1). 
Table 1

Baseline characteristics among different smoke and drink groups, by sex

\section{Non- $\quad$ Non- $\quad$ Smoker/Non- Smoker/Drinker $P$ smoker/Non- smoker/Drinker Drinker drinker}

\section{All participants}

\begin{tabular}{|c|c|c|c|c|c|}
\hline $\begin{array}{l}\text { Number of } \\
\text { subjects }\end{array}$ & 8029 & 2159 & 2309 & 4583 & \\
\hline Age(years) & $50.30(10.06)$ & $59.26(9.83)$ & $60.89(10.03)$ & $59.57(9.37)$ & $\begin{array}{l}< \\
0.001\end{array}$ \\
\hline Age group & & & & & $<.001$ \\
\hline$<50$ & 1798 (22.39) & $483(22.37)$ & 395 (17.11) & 868 (18.94) & \\
\hline $50-59$ & 2885 (35.93) & 754 (34.92) & 795 (34.43) & $1714(37.40)$ & \\
\hline $60-69$ & 2077 (25.87) & 599 (27.74) & $636(27.54)$ & $1321(28.82)$ & \\
\hline $70-79$ & $954(11.88)$ & $247(11.44)$ & $392(16.98)$ & $555(12.11)$ & \\
\hline$\geq 80$ & 315 (3.92) & $76(3.52)$ & 91 (3.94) & 125 (2.73) & \\
\hline $\begin{array}{l}\text { Middle school } \\
\text { education (\%) }\end{array}$ & 2109 (26.32) & $669(31.00)$ & 738 (31.99) & $1752(38.28)$ & \\
\hline Rural (\%) & $6236(77.75)$ & 1656 (76.74) & 1839 (79.71) & $3603(78.65)$ & 0.064 \\
\hline Married (\%) & 6838 (85.17) & $1896(87.86)$ & $1966(85.15)$ & $4152(90.60)$ & $\begin{array}{l}< \\
0.001\end{array}$ \\
\hline Hypertension (\%) & 3159 (39.34) & $834(38.63)$ & $810(35.08)$ & $1764(38.49)$ & 0.003 \\
\hline Dyslipidemia (\%) & 2630 (32.76) & $659(30.52)$ & 770 (33.35) & 1359 (29.65) & 0.001 \\
\hline Diabetes (\%) & 653 (8.13) & 178 (8.24) & 167 (7.23) & $288(6.28)$ & 0.001 \\
\hline $\begin{array}{l}\text { Overweight or } \\
\text { obesity }(\%)^{*}\end{array}$ & 2886 (46.29) & 712 (42.61) & $588(32.15)$ & 1118 (31.98) & $<.001$ \\
\hline $\begin{array}{l}\text { History of CVD } \\
(\%)\end{array}$ & $1211(15.08)$ & $271(12.55)$ & $333(14.42)$ & $556(12.13)$ & $<.001$ \\
\hline \multicolumn{6}{|l|}{ Male } \\
\hline $\begin{array}{l}\text { Number of } \\
\text { subjects }\end{array}$ & 1091 & 1083 & 1767 & 4391 & \\
\hline Age(years) & $61.42(10.47)$ & $59.20(9.96)$ & 60.17 (9.75) & $59.37(9.26)$ & $\begin{array}{l}<.001 \\
0 .\end{array}$ \\
\hline Age group & & & & & $\begin{array}{l}< \\
0.001\end{array}$ \\
\hline
\end{tabular}




\begin{tabular}{|c|c|c|c|c|c|}
\hline & $\begin{array}{l}\text { Non- } \\
\text { smoker/Non- } \\
\text { drinker }\end{array}$ & $\begin{array}{l}\text { Non- } \\
\text { smoker/Drinker }\end{array}$ & $\begin{array}{l}\text { Smoker/Non- } \\
\text { Drinker }\end{array}$ & Smoker/Drinker & $P$ \\
\hline$<50$ & $198(18.15)$ & $253(23.36)$ & 319 (18.05) & 855 (19.47) & \\
\hline $50-59$ & $332(30.43)$ & 367 (33.89) & $638(36.11)$ & 1655 (37.69) & \\
\hline $60-69$ & $308(28.23)$ & $299(27.61)$ & $490(27.73)$ & $1254(28.56)$ & \\
\hline $70-79$ & $202(18.52)$ & $124(11.45)$ & 264 (14.94) & $517(11.77)$ & \\
\hline$\geq 80$ & $51(4.67)$ & 40 (3.69) & $56(3.17)$ & $110(2.51)$ & \\
\hline $\begin{array}{l}\text { Middle school } \\
\text { education (\%) }\end{array}$ & $428(39.34)$ & $460(42.51)$ & $668(37.83)$ & 1724 (39.32) & $<.001$ \\
\hline Rural (\%) & 777 (71.22) & 772 (71.35) & $1390(78.75)$ & 3441 (78.38) & $\dot{0}_{0.001}$ \\
\hline Married (\%) & $978(89.64)$ & 1003(92.70) & 1563(88.46) & 4008(91.28) & $\begin{array}{l}< \\
0.001\end{array}$ \\
\hline Hypertension (\%) & $402(36.85)$ & 425 (39.24) & $570(32.26)$ & 1671 (38.06) & $\begin{array}{l}<.001 \\
0.00\end{array}$ \\
\hline Dyslipidemia (\%) & 356 (32.63) & 333 (30.75) & $573(32.43)$ & $1300(29.61)$ & 0.077 \\
\hline Diabetes (\%) & 76 (6.97) & 95 (8.77) & $116(6.56)$ & $275(6.26)$ & 0.031 \\
\hline $\begin{array}{l}\text { Overweight or } \\
\text { obesity }(\%)^{*}\end{array}$ & $300(38.56)$ & 342 (42.59) & $408(29.76)$ & 1058 (31.63) & $\begin{array}{l}< \\
0.001\end{array}$ \\
\hline $\begin{array}{l}\text { History of CVD } \\
(\%)\end{array}$ & 139 (12.74) & $143(13.20)$ & $197(11.15)$ & $511(11.64)$ & 0.292 \\
\hline \multicolumn{6}{|l|}{ Female } \\
\hline $\begin{array}{l}\text { Number of } \\
\text { subjects }\end{array}$ & 6938 & 1076 & 542 & 192 & \\
\hline Age(years) & $58.97(9.96)$ & $59.32(9.70)$ & $63.22(10.56)$ & $64.30(10.49)$ & $\begin{array}{l}< \\
0.001\end{array}$ \\
\hline Age group & & & & & $\begin{array}{l}< \\
0.001\end{array}$ \\
\hline$<50$ & $1600(23.06)$ & $230(21.38)$ & 76 (14.02) & $13(6.77)$ & \\
\hline $50-59$ & $2553(36.80)$ & 387 (35.97) & 157 (28.97) & 59 (30.73) & \\
\hline $60-69$ & 1769 (25.50) & $300(27.88)$ & $146(26.94)$ & 67 (34.90) & \\
\hline $70-79$ & $752(10.84)$ & $123(11.43)$ & $128(23.62)$ & 38 (19.79) & \\
\hline$\geq 80$ & $264(3.81)$ & $36(3.35)$ & $35(6.46)$ & $15(7.81)$ & \\
\hline
\end{tabular}




\begin{tabular}{|c|c|c|c|c|c|}
\hline & $\begin{array}{l}\text { Non- } \\
\text { smoker/Non- } \\
\text { drinker }\end{array}$ & $\begin{array}{l}\text { Non- } \\
\text { smoker/Drinker }\end{array}$ & $\begin{array}{l}\text { Smoker/Non- } \\
\text { Drinker }\end{array}$ & Smoker/Drinker & $P$ \\
\hline $\begin{array}{l}\text { Middle school } \\
\text { education (\%) }\end{array}$ & $1681(24.27)$ & 209 (19.42) & 70 (12.94) & 28 (14.58) & $<0.001$ \\
\hline Rural (\%) & 5459 (78.77) & $884(82.16)$ & 449 (82.84) & $162(84.82)$ & 0.003 \\
\hline Married (\%) & $5860(84.46)$ & 893 (82.99) & 403 (74.35) & $144(75.00)$ & $<.001$ \\
\hline Hypertension (\%) & 2757 (39.74) & 409 (38.01) & $240(44.28)$ & 93 (48.44) & 0.008 \\
\hline Dyslipidemia (\%) & 2274 (32.78) & $326(30.30)$ & 197 (36.35) & 59 (30.73) & 0.092 \\
\hline Diabetes (\%) & 577 (8.32) & $83(7.71)$ & $51(9.41)$ & $13(6.77)$ & 0.582 \\
\hline $\begin{array}{l}\text { Overweight or } \\
\text { obesity }(\%)^{*}\end{array}$ & 2586 (47.39) & $370(42.63)$ & $180(39.30)$ & 60 (39.74) & $\begin{array}{l}< \\
0.001\end{array}$ \\
\hline $\begin{array}{l}\text { History of CVD } \\
(\%)\end{array}$ & $1072(15.45)$ & $128(11.90)$ & $136(25.09)$ & $45(23.44)$ & $<.001$ \\
\hline
\end{tabular}

Table 2 shows the joint effect of smoke and drink on all-cause mortality. Generally, the odds of all-cause mortality was higher in smoker/non-drinker group (Unadjusted analysis: $\mathrm{OR}=1.28 ; 95 \% \mathrm{Cl}$ : 1.06-1.54). Similar result was found in subgroup analysis, there was a 2.4-fold (Unadjusted analysis: $O R=2.34$; 95\%Cl: 1.60-3.43) increase in the odds of all-cause mortality for smoker/non-drinker in female. The odds of all-cause mortality was higher in smoker/drinker, smoker/drinker increased the odds of all-cause mortality with an OR value equal to 1.75 (95\% Cl: $1.39-2.19$, unadjusted analysis). The subgroup analysis in female, the OR value was 3.14 ( $95 \% \mathrm{Cl}$ : $1.82-5.14$, unadjusted analysis). In multivariable regression, after controlling for the confounders, the associations remained significant. The ORs value of all-cause mortality were 1.47 (95\% Cl: 1.03-2.08) and 1.51 (95\% Cl: 1.09-2.10) in smoker/non-drinker and smoker/drinker separately. In the subgroup analysis, the smoker/non-drinker $(\mathrm{OR}=1.56 ; 95 \% \mathrm{Cl}$ : 0.992.44) and smoker/drinker $(\mathrm{OR}=2.02 ; 95 \% \mathrm{Cl}$ : $0.95-4.30)$ in female increased odds of all-cause mortality compared with non-smoker/non-drinker in female. Although the associations were not significant after controlling for confounders, the lower limits of $95 \% \mathrm{Cl}$ were pretty close to 1 . 
Table 2

Odds ratio of all-cause mortality among different smoke and drink group, by sex

\begin{tabular}{|c|c|c|c|c|}
\hline & $\begin{array}{l}\text { Non-smoker/Non- } \\
\text { drinker }\end{array}$ & $\begin{array}{l}\text { Non- } \\
\text { smoker/Drinker }\end{array}$ & $\begin{array}{l}\text { Smoker/Non- } \\
\text { Drinker }\end{array}$ & Smoker/Drinker \\
\hline \multicolumn{5}{|l|}{$\begin{array}{l}\text { All } \\
\text { participants }\end{array}$} \\
\hline Unadjusted & 1.00 & $0.99(0.62,1.56)$ & $1.28(1.06,1.54)$ & $\begin{array}{l}1.75(1.39 \\
2.19)\end{array}$ \\
\hline Adjusted* & 1.00 & $1.06(0.61,1.86)$ & $1.47(1.03,2.08)$ & $\begin{array}{l}1.51(1.09 \\
2.10)\end{array}$ \\
\hline \multicolumn{5}{|l|}{ Male } \\
\hline Unadjusted & 1.00 & $0.78(0.37,1.65)$ & $0.83(0.60,1.15)$ & $\begin{array}{l}1.11(0.77, \\
1.61)\end{array}$ \\
\hline Adjusted* & 1.00 & $1.18(0.50,2.80)$ & $1.42(0.96,2.10)$ & $\begin{array}{l}1.46(0.94 \\
2.26)\end{array}$ \\
\hline \multicolumn{5}{|l|}{ Female } \\
\hline Unadjusted & 1.00 & $0.89(0.57,1.37)$ & $2.34(1.60,3.43)$ & $\begin{array}{l}3.14(1.82, \\
5.41)\end{array}$ \\
\hline Adjusted* & 1.00 & $0.87(0.50,1.50)$ & $1.56(0.99,2.44)$ & $\begin{array}{l}2.02(0.95 \\
4.30)\end{array}$ \\
\hline
\end{tabular}

Compared with non-smoker and non-drinker, smoker/drinker increased the odds of premature death in unadjusted analysis ( $\mathrm{OR}=2.12 ; 95 \% \mathrm{Cl}$ : 1.46-3.08). After controlling for confounders, the OR value was 3.14 (95\% Cl: $1.56-6.34)$. The odds of premature death was 2.2 -fold (Adjusted analysis: OR $=2.17 ; 95 \% \mathrm{Cl}$ : 1.11-4.22) higher in smoker/non-drinker. In unadjusted analysis, the OR of premature death in smoker/non-drinker was 1.49 (95\% Cl: $0.90-2.45)$. In the subgroup analysis, there was a 5 -fold (Unadjusted analysis: $\mathrm{OR}=5.36 ; 95 \% \mathrm{Cl}$ : 2.32-12.36; Adjusted analysis: $\mathrm{OR}=4.95 ; 95 \% \mathrm{Cl}$ : 2.00-12.27) increase in the odds of premature death for female smoker/drinker. The odds of all-mortality and premature death were similar and not significant between non-smoker/non-drinker group and nonsmoker/drinker group. (Table 2, Table 3) 
Table 3

Odds ratio of premature death among different smoke and drink groups, by sex 1

\begin{tabular}{|c|c|c|c|c|}
\hline & $\begin{array}{l}\text { Non-smoker/Non- } \\
\text { drinker }\end{array}$ & $\begin{array}{l}\text { Non- } \\
\text { smoker/Drinker }\end{array}$ & $\begin{array}{l}\text { Smoker/Non- } \\
\text { Drinker }\end{array}$ & Smoker/Drinker \\
\hline \multicolumn{5}{|l|}{$\begin{array}{l}\text { All } \\
\text { participants }\end{array}$} \\
\hline Unadjusted & 1.00 & $0.84(0.48,1.46)$ & $1.49(0.90,2.45)$ & $\begin{array}{l}2.12(1.46, \\
3.08)\end{array}$ \\
\hline Adjusted $^{2}$ & 1.00 & $1.11(0.57,2.15)$ & $2.17(1.11,4.22)$ & $\begin{array}{l}3.14(1.56, \\
6.34)\end{array}$ \\
\hline \multicolumn{5}{|l|}{ Male } \\
\hline Unadjusted & 1.00 & $0.29(0.11,0.83)$ & $0.69(0.28,1.68)$ & $\begin{array}{l}1.01(0.46, \\
2.22)\end{array}$ \\
\hline Adjusted ${ }^{2}$ & 1.00 & $0.50(0.17,1.47)$ & $1.17(0.46,2.93)$ & $\begin{array}{l}1.57(0.71 \\
3.47)\end{array}$ \\
\hline \multicolumn{5}{|l|}{ Female } \\
\hline Unadjusted & 1.00 & $1.31(0.66,2.61)$ & $2.20(0.99,4.89)$ & $\begin{array}{l}5.36(2.32 \\
12.36)\end{array}$ \\
\hline Adjusted $^{2}$ & 1.00 & $1.25(0.59,2.66)$ & $2.01(0.83,4.83)$ & $\begin{array}{l}4.95(2.00 \\
12.27)\end{array}$ \\
\hline \multicolumn{5}{|c|}{$\begin{array}{l}{ }^{1} \text { Premature death defined as mortality before age } 72.7 \text { years in men and } 76.9 \text { years in women, which } \\
\text { were the average life expectancies in China in } 2011 \text {. however, Age of death can only be estimated } \\
\text { among CHALS } 2013 \text { follow up. }\end{array}$} \\
\hline \multicolumn{5}{|c|}{$\begin{array}{l}2 \text { Adjusted variables include gender, age, middle school education, residence status, marital status, } \\
\text { hypertension, dyslipidemia, diabetes, history of CVD, overweight or obesity. }\end{array}$} \\
\hline
\end{tabular}

\section{Discussion}

In our present analysis, we found that alcohol consumption could strengthen the harmful effect from cigarette smoking. Our estimate indicate that compared with the nonsmoker and non-smoker, those who both smoke and drink could have $75 \%$ higher risk of death or $112 \%$ more likely to die early. We have also indicated that women are likely to have higher risk of all-cause mortality or premature death from the combine effect of tobacco smoke and drink use than men.

Alcohol use has been reported to increase risk of all-cause mortality; however this is generally found to be varied by the amount consumed with a $\mathrm{U}$ or $\mathrm{J}$ shape being reported. This usually indicated as a lower overall mortality among subject with light to moderate drinking while a higher rate of death among those heavy drinkers $(9,10)$. However, A study from a large cohort showed that the beneficial effect from the light and moderate alcohol use was offset by cigarette smoke and the risk of total mortality increase with 
the smoking intensity from $0.8(95 \% \mathrm{Cl}: 0.6,1.0)$ for non-smoker to $1.0(0.9,1.2)$ for moderate smokers and $1.4(95 \% \mathrm{Cl}: 1.2,1.7)$ for heavy smokers $(18)$. The negative combined effect from smoking and drinking was also reported in other studies $(19,20)$. Our study was consistent with these findings in general and found that the highest risk was observed among those who both smoke and drink alcohol.

Premature death of a middle-aged person is often devastating to a household and is often associated with decreased income, and mortality in the affected families. Identification of the associated risk is crucial to health planning and policy development(21). In our study, we also tried to explore the adverse association of this synergy effect of cigarette smoking and alcohol consumption with premature death. Consistent with the results for all-cause mortality, we found that, compared with non-smoker and nondrinker, smoker and drinker was significantly associated with early death, despite of the non-significance among subgroup by gender due to the small sample size.

It is noteworthy that the gender difference was found in both all-cause mortality and premature death. It has been noted that women smokers and/or drinker are more likely to have greater mortality risk. This phenomena has been reported in previous publications $(1,4,9,19,22,23)$ assessing smoking or drink risk, even among those with existing diseases, such as diabetes (24). The mechanisms underlying the sex difference in mortality may be attribute to their biological or related to differences in smoking behaviour between men and women. It seems that men are likely to be exposed more risks than women, which may confer the risk from smoke or drink use. This can be told from our data. In our study, we found that $52.7 \%$ of men were both cigarette smokers and alcohol drinkers, whereas, only $2.19 \%$ was found in women.

Several limitations of the study should be mentioned. First, due to the limited information from this public database, further analysis by drink amount or the cause of death, such as CVD mortality or cancer mortality are not available. Several studies have shown that the effect of alcohol consumption on mortality is generally found to depend on the amount consumed and presented differently by causespecific mortality. However, this was argued by other studies suggesting that the nonlinear relationship is explained by the study design or selected bias across age-sex strata $(11,12)$. Second, this study is an ongoing study and the follow-up period is relative short. Thus, the statistical power is limited for subgroup analysis by gender. Third, as date of death was only released for data of 2013 follow-up survey, information on age of death and premature death can only be obtained for this survey.

In summary, our present analysis indicated that alcohol consumption could further increase the risk of total death or premature death from smoking. Further studies are needed to confirm the higher risk of death from joint effect of smoking and drink among female population.

\section{Declarations}

\section{Acknowledgments}

We would like to thank the CHARLS (China Health and Retirement Longitudinal Study) study participants and trial investigators. This article was prepared using research materials obtained from the Peking 
University Open Research Data Platform.

Contributors: $\mathrm{HZ}$ and XB did the analysis and drafted the initial manuscript. $\mathrm{NZ}$ and $\mathrm{CL}$ critically reviewed and revised the manuscript. KY critically reviewed the results of analyses, and reviewed and revised the manuscript. All authors were responsible for the study concept and design and approved the final draft of the manuscript. $\mathrm{KY}$ is the guarantor. The corresponding author attests that all listed authors meet authorship criteria and that no others meeting the criteria have been omitted.

Funding: No funding.

Competing interests: No conflicts of interest.

Ethical approval: Since we were performing secondary analyses of deidentified data, we sought no approval from institutional review boards.

\section{References}

1. Hackshaw A, Morris JK, Boniface S, et al. Low cigarette consumption and risk of coronary heart disease and stroke: meta-analysis of 141 cohort studies in 55 study reports. BMJ. 2018;360:j5855.

2. Doll R, Peto R, Boreham J, et al. Mortality in relation to smoking: 50 years' observations on male British doctors. BMJ. 2004;328(7455):1519.

3. Thun MJ, Carter BD, Feskanich D, et al. 50-year trends in smoking-related mortality in the United States. N Engl J Med. 2013;368(4):351-64.

4. Zheng W, McLerran DF, Rolland BA, et al. Burden of total and cause-specific mortality related to tobacco smoking among adults aged $>/=45$ years in Asia: a pooled analysis of 21 cohorts. PLoS Med. 2014;11(4):e1001631.

5. Collaborators GBDRF, Forouzanfar MH, Alexander L, et al. Global, regional, and national comparative risk assessment of 79 behavioural, environmental and occupational, and metabolic risks or clusters of risks in 188 countries, 1990-2013: a systematic analysis for the Global Burden of Disease Study 2013. Lancet. 2015;386(10010):2287-323.

6. Collaborators GBDT. Smoking prevalence and attributable disease burden in 195 countries and territories, 1990-2015: a systematic analysis from the Global Burden of Disease Study 2015. Lancet. 2017;389(10082):1885-906.

7. He J, Gu D, Wu X, et al. Major causes of death among men and women in China. N Engl J Med. 2005;353(11):1124-34.

8. Collaborators GBDA. Alcohol use and burden for 195 countries and territories, 1990-2016: a systematic analysis for the Global Burden of Disease Study 2016. Lancet. 2018;392(10152):101535.

9. Xi B, Veeranki SP, Zhao M, et al. Relationship of Alcohol Consumption to All-Cause, Cardiovascular, and Cancer-Related Mortality in U.S. Adults. J Am Coll Cardiol. 2017;70(8):913-22. 
10. Wood AM, Kaptoge S, Butterworth AS, et al. Risk thresholds for alcohol consumption: combined analysis of individual-participant data for 599912 current drinkers in 83 prospective studies. Lancet. 2018;391(10129):1513-23.

11. Knott CS, Coombs N, Stamatakis E, et al. All cause mortality and the case for age specific alcohol consumption guidelines: pooled analyses of up to 10 population based cohorts. Bmj-Brit Med J. 2015;350.

12. Holmes MV, Dale CE, Zuccolo L, et al. Association between alcohol and cardiovascular disease: Mendelian randomisation analysis based on individual participant data. Bmj-Brit Med J. 2014;349.

13. Stockwell T, Zhao J, Panwar S, et al. Do "Moderate" Drinkers Have Reduced Mortality Risk? A Systematic Review and Meta-Analysis of Alcohol Consumption and All-Cause Mortality. J Stud Alcohol Drugs. 2016;77(2):185-98.

14. Zhao Y, Hu Y, Smith JP, et al. Cohort profile: the China Health and Retirement Longitudinal Study (CHARLS). Int J Epidemiol. 2014;43(1):61-8.

15. Khera R, Lu Y, Lu J, et al. Impact of 2017 ACC/AHA guidelines on prevalence of hypertension and eligibility for antihypertensive treatment in United States and China: nationally representative cross sectional study. BMJ. 2018;362:k2357.

16. Zhang X, CHen X, Ran G, et al. Adult children's support and self-esteem as mediators in the relationship between attachment and subjective well-being in older adults. Personality Individ Differ. 2016;97:229-33.

17. Zhao YS, Yang J, Giles G, et al. China health and retirement longitudinal study-2011-2012 national baseline users' guide. Beijing: National School of Development, Peking University. 2013:1-56.

18. Xu WH, Zhang XL, Gao YT, et al. Joint effect of cigarette smoking and alcohol consumption on mortality. Prev Med. 2007;45(4):313-9.

19. Martelin T, Makela P, Valkonen T. Contribution of deaths related to alcohol or smoking to the gender difference in life expectancy: Finland in the early 1990s. Eur J Public Health. 2004;14(4):422-7.

20. Ebbert JO, Janney CA, Sellers TA, et al. The association of alcohol consumption with coronary heart disease mortality and cancer incidence varies by smoking history. J Gen Intern Med. 2005;20(1):1420.

21. Peto R, Lopez AD, Norheim OF. Halving premature death. Science. 2014;345(6202):1272.

22. Hurley MA. Light smoking at base-line predicts a higher mortality risk to women than to men; evidence from a cohort with long follow-up. Bmc Public Health. 2014;14:95.

23. Taghizadeh N, Vonk JM, Boezen HM. Lifetime Smoking History and Cause-Specific Mortality in a Cohort Study with 43 Years of Follow-Up. PLoS One. 2016;11(4):e0153310.

24. Qin R, Chen T, Lou Q, et al. Excess risk of mortality and cardiovascular events associated with smoking among patients with diabetes: meta-analysis of observational prospective studies. Int $\mathrm{J}$ Cardiol. 2013;167(2):342-50. 